\title{
LA DESCRIPCIÓN DE LAS AVES EN LA OBRA DEL MADRILEÑO GONZALO FERNÁNDEZ DE OVIEDO
}

\author{
Raquel Álvarez Peláez \\ Dpto. de H. ${ }^{a}$ de la Ciencia - Centro de Estudios Históricos, CSIC - C/ Duque de Medinaceli 6, Madrid
}

\section{RESUMEN}

En este trabajo se estudian las descripciones de las aves realizadas por Gonzalo Fernández de Oviedo, uno de los más tempranos y más agudos observadores de la naturaleza americana. Para valorar de forma adecuada sus descripciones he comparado algunas de ellas con las de otros naturalistas de la época.

\section{SUMMARY}

This paper is dedicated to analize the descriptions of birds carried out by Gonzalo Fernández de Oviedo, one of the earliest and keenner observers of the American nature. In order to value their descriptions on appropriate way I have compared some of them with those of other naturalists of the time.

GONZALO FERNÁNDEZ DE OVIEDO Y VALDÉS (1478-1557) fue, por lo que se desprende de su biografía, un personaje representativo de un tiempo nuevo, el Renacimiento, y también del establecimiento progresivo de un poder central que iría organizando, con el tiempo, toda una compleja administración en la que se harían fuertes personajes surgidos de un medio relativamente humilde, o por lo menos no aristocrático ni económicamente poderoso, pero que, adquiriendo conocimientos y por propios méritos personales, se harían necesarios para ese desarrollo administrativo que culminó en el reinado de Felipe II. Fernández de Oviedo es un temprano representan- 


\section{RAQUEL ÁLVAREZ PELÁEZ}

te de ese tipo de gente, y luchó con entusiasmo para ascender en la escala social y económica. Como se ha señalado en las diferentes biografías existentes ${ }^{1}$-interesantes, pero creo que todavía insuficientes para transmitirnos toda la riqueza del personaje y los incidentes de su vida- Oviedo, por relaciones familiares, creció en Navarra, en casa del segundo duque de Villahermosa, Alonso de Aragón, residente en la villa de Cortes, perteneciente a la comarca de Tudela. Nos dice Pérez de Tudela que Oviedo debía tener unos doce años cuando pasó como paje al servicio del joven aristócrata, de aproximadamente la misma edad. Según parece, esta gente era amante de las letras y las artes, eran, digamos, uno de los núcleos aristocráticos cultos de la época, lo que haría que la formación ilustrada de nuestro personaje comenzara muy temprano. Lo cierto es que a partir de ese momento su vida va a estar muy ligada a la corte y a la aristocracia, tanto en España como en Italia. Importante fue su paso al servicio del príncipe don Juan, el amado hijo de los Reyes Católicos, hasta su temprana muerte. Importante, además, desde el punto de vista de su temprana relación con las noticias de América, pues gracias a su situación conoció a los hijos de Cristóbal Colón, y al mismo Almirante a su regreso de las Indias que acababa de descubrir, en Barcelona, donde se encontraba la corte. Un Colón triunfador, que llega acompañado de indios y de animales exóticos, que bien debía haber estimulado la imaginación de un joven despierto y observador como Oviedo. Antonello Gerbi, en su magnífico litro La naturaleza de las Indias Nuevas, atribuye, en cierta medida, a Italia, la agudeza de la curiosidad y el don de la observación de Oviedo. Cierto es que Italia debía ser enormemente estimulante - como sigue siendo - con una cultura rica - en gran medida, puerta entre oriente y occidente- imaginativa y vibrante. Pero también es cierto que Oviedo demostró, desenvolviéndose en muy diversos ambientes — desde las cultas Milán, Ferrara, Mantua, Roma o Nápoles, hasta las

1 Biografías: Amador de los Ríos, en su Introducción a la Historia General y Natural, (1851-55), Pérez de Tudela Bueso, en su Introducción a la misma obra (1959), Antonello Gerbi, en La naturaleza de las Indias Nuevas, (1972) o Manuel Ballesteros, en su Gonzalo Fernández de Oviedo, (1981), y en la Introducción a la edición del Sumario de la Natural Historia de las Indias, editado en 1986, además del número de 1957 (números 69-70) de la Revista de Indias a él dedicado, en el que escriben Ballesteros, sobre las descripciones de corte etnológico de Oviedo, Pérez de Tudela, Álvarez López su conocido trabajo sobre la historia natural, José de la Peña y Cámara, Ernesto J. Castillero, Roberto Ferrando y Josefina Zoraida, y tantos y tantos trabajos que se refieren a sus innumerables historias, todas contadas con entusiamo, con amor al detalle e interés de lo que se refiere, sea naturaleza o hechos de los hombres. Las publicaciones más recientes siguen realzando el interés de los escritos de Fernández de Oviedo, tanto en su momento como en la actualidad. Ello lo demuestran los trabajos de Pardo Tomás, «Obras españolas sobre historia natural y materia médica americanas en la Italia del siglo XVI», publicado en la revista Asclepio, vol. XLIII, 1991, fasc.1, pp. 51-94, o las páginas y capítulos dedicados al madrileño y su obra en Las primeras noticias sobre plantas americanas en las relaciones de viajes y crónicas de Indias, (1493-1553). 
selvas tropicales de Centroamérica- que era un ser adaptable y receptivo a todo entorno, cualquiera fuera su característica.

La vida de Oviedo pasó por diversas situaciones personales gratas e ingratas, como trascurre toda vida humana, viviendo el tipo de avatares que se daban en un siglo XVI dinámico y con grandes novedades. Y más variada fue su vida pues Fernández de Oviedo era una persona que buscaba, con gran ambición, ascender en la escala social a partir de una situación humilda. Pueden consultarse las diversas biografías ya reseñadas para conocer más detales de su interesante vida. Yo sólo quiero señalar dos aspectos más. El primero, que a su regreso a España, después de sus años en Italia, y por estar al servicio del duque de Calabria, estuvo en contacto con la magnífica biblioteca de este culto aristócrata, expulsado de Nápoles por la corona española, la Biblioteca d'Aragona, heredada de Alfonso V de Aragón. En esta biblioteca pudo haber manejado Oviedo a, por ejemplo, su admirado Plinio, que le serviría de guía para organizar sus observaciones de la naturaleza americana. En segundo lugar, decir que, después de la temprana muerte de su primera mujer y del fracaso de la expedición a Italia del Gran Capitán, Gonzalo Fernández de Córdoba, a quien Oviedo iba a acompañar como Secretario, nuestro personaje decide pasar a las Indias a probar fortuna. En su preparación para el viaje a Italia se había gastado, según dice, sus ahorros, y ya nada le ligaba a España. Consigue un nombramiento de Veedor, controlador del oro de la llamada, justamente por razón del mineral, Castilla del Oro: la Provincia de Cueva, el Darién, Veragua, o sea, tierras de Colombia y de Panamá. Y se embarcó en 1514 con Pedrarias Dávila, que iba a poner orden en la situación creada por Núñez de Balboa en el Darién, que por apoyo popular estaba gobernando en la región, y había organizado un Cabildo popular. Aquí comenzaría la vida americana de Gonzalo Fernández de Oviedo y Valdés.

No es este lugar para hacer un repaso de la vida de este personaje, solamente quería que quedara constancia de que cuando se marcha a América contaba ya con un importante bagaje de experiencias y conocimientos sobre Europa y América. En el Nuevo Mundo sufrirá penalidades, pero tendrá también recompensas, y después de muchos avatares y de muchos viajes de ida y vuelta entre ambos continentes - seis, en concreto- pasará muchos años y terminará su vida como gobernador de la fortaleza de Santo Domingo, el 26 de julio de 1557, a los setenta y nueve años de edad.

Fernández de Oviedo demostró en sus escritos, como todo el mundo señala, que era un impresionante observador y un excelente narrador. sus ojos, por decirlo de alguna manera, estaban llenos de posibilidades, tenía la capacidad de ver sin imponer rígidos esquemas o firmes conocimientos librescos. En sus obras, pues, encontramos todos los detalles de lo que está sucediendo, el ambiente donde se produce, las características del comportamiento de hombres y demás especies.

Quizás es producto de una epoca en que quizás se daba un tipo de unidad de la naturaleza, de relación del hombre con su entorno natural, en que había un cierto 


\section{RAQUEL ÁLVAREZ PELÁEZ}

equilibrio. El hombre iba adquiriendo una cierta capacidad de distanciamiento, se iba liberando de la opresión creada por una naturaleza rígidamente estructurada por un Dios, pero al mismo tiempo no tenía todavía capacidad de dominio y destrucción sobre esa naturaleza, sobre su entorno. Indudablemente se consideraba que la naturaleza era para que el hombre la utilizara, para eso había sido creada por Dios, pero el hombre todavía no podía hacerlo de forma excesiva, no tenía los medios técnicos. Había una cierta sensación de estar de igual a igual frente a los otros seres, todos creados por Dios, aunque el hombre tuviera su alma superior y su posibilidad de salvación, aunque también de pecado, que el resto de los seres vivientes van perdiendo; los simbolismos positivos y negativos de animales, plantas y monstruos irán desapareciendo poco a poco. La naturaleza todavía inspiraba respeto, placer, emociones. Y todavía no se había racionalizado la relación con ella, como sucederá ya en el siglo XVIII, con el pensamiento ilustrado, ciencia que ya comienza a ser dura, despojada de relación estética y afectiva con el entorno. Nuestra época es la consecuencia de ese camino recorrrido. Oviedo es un representante de una actitud de sentimiento frente a la naturaleza, a pesar de ser un observador agudo y detallista, sin que exista por ello contradicción. Mutis es un ejemplo de pensamiento racionalista que sólo ve géneros y especies en las maravillosas selvas de Colombia. Pero también es diferente la manera de ver la naturaleza de Hernández, y compararemos algunas de las descripciones de ambos observadores, el madrileño y el toledano, para que veamos claramente la diferencia ente un Oviedo no científico y un Hernández científico. Creo que esto permitirá resaltar esa innata capacidad de Fernández de Oviedo para la observación, por encima de cualquiera formación autodidacta que hubiera obtenido. Pienso que Plinio fue simplemente una guía para ordenar sus descripciones, su material acumulado por sus observaciones. Posiblemente Oviedo, consciente del interés que despertaría y que despertaba la descripción de maravillosas nuevas especies de plantas y animales, buscara hacer un apartado, desligando estas descripciones del texto global. Eso fue, seguramente, su actitud al preparar el Sumario, y después la primera parte de la Historia General de las Indias.

Y todo lo observa con detalle y lo cuenta de la misma forma. Oviedo no era un estudioso de la naturaleza, ni un médico, ni siquiera un jardinero. Sus observaciones y descripciones no buscaban profundizar en el estudio de la naturaleza de las plantas, animales u hombres. Pero era un hombre inteligente, que respondía a los intereses de su tiempo así como a sus propios intereses. Luchó por ascender socialmente, y creo que lo consiguió, pues aun cuando tuvo una vida azarosa y con problemas de todo tipo, no fue mucho más desgraciada que las de sus congéneres; por el contrario, podría decirse que, a pesar de las circunstancias amargas de la vida, como la muerte de sus sucesivas esposas, consiguió una situación estable, agradable y vivió muchos años en Santo Domingo, sin privarse, por otra parte, de hacer repetidos viajes a la Península. Su puesto de Gobernador de la plaza de Santo Domingo le permitió, ade- 
más, escribir abundantemente y dejarnos unas magníficas crónicas, maravillosamente ambientadas en una sorprendente y deliciosa naturaleza, a la que era, estéticamente, evidentemente muy sensible. Como hombre inteligente, que debía, para situarse y valorarse delante del mundo y de las autoridades que fueran, señalar el interés e importancia de las cosas que describía, indicaba para que podían ser, o eran, útiles.

Fernández de Oviedo escribió primero crónicas históricas sobre los reyes, después, obras sobre América, insistiendo siempre en el valor de la observación directa, de que todo era su propia vivencia y «vista de ojo». Y sus obras, como siempre, iban dirigidas, ofrecidas a los reyes. Hombre hábil para relacionarse con príncipes y poderosos, como demostró a lo largo de su vida, de su búsqueda de situación, siendo criado o servidor de muchos, desde el hijo de los Católicos Reyes hasta, casi, de Gonzalo Fernández de Córdoba, demostró saber moverse también en situaciones tan diferentes como la de la ocupación del Nuevo Mundo, con todas sus luchas y problemas, consiguiendo, como he indicado más arriba, instalarse en una buena situación en aquellas tierras.

La mayoría de los escritos de Fernández de Oviedo permanecieron inéditos, siendo publicados algunos parcialmente, ya que el único que apareció completo fue lo que él mismo consideraba un resumen de sus observaciones sobre la naturaleza americana, el De la Natural Historia de las Indias, o Sumario de la Natural Historia de las Indias, que redactó y publicó en uno de sus regresos a España —en 1526- para impresionar a Carlos V. Esta obra tuvo muy amplia repercusión en España y en Europa, siendo traducida a varios idiomas e incluída en la obra del veneciano Giovan Battista Ramusio Delle Navigationi et viaggi ${ }^{2}$, editado por primera vez $-\mathrm{y}$ sólo el primer volumen - en 1550, igualmente de gran difusión, pues incluía importantes relatos y noticias de los viajes que se realizaban en la época. Las relaciones entre Oviedo, Fracastoro, Pietro Bembo y Priuli han sido descritas, entre otros, por Antonello Gerbi, Amador de los Ríos, Pérez de Tudela, Ballesteros y Pardo Tomás ${ }^{3}$. El Sumario ha sido reeditado varias veces ${ }^{4}$, aunque, pienso, nunca como se merece, con una buena edición crítica. Desde el punto de vista de la historia natural, es interesante la publicación realizada por Enrique Álvarez López, de 1942, por sus anotaciones sobre las especies descritas en la obra, y quizás más aún por su manera de valorar, situado en su época, el esfuerzo descriptivo del madrileño. Esta justa valoración pue-

2 Ramusio, G.B. $(1550,1556,1560)$, Navigationi et viaggi, Venezia, 3 vols.

3 PARDO TOMÁs, J., (1991), «Obras españolas sobre historia natural y materia médica americanas en la Italia del siglo XVI», Asclepio, vol. XLIII, 1991, fasc.1, pp. $62-69$

4 El Sumario fue integrado por ANDRÉs GONZÁlez BARCIA en el Tomo I de los Historiadores primitivos de las Indias Occidentales, Madrid, 1749; en 1942 se publica De la Natural Historia de las Indias, con un Estudio preliminar y Notas por ENRIQUE ÁlvarEZ LóPEZ, Ed Summa.; en 1986 aparece el Sumario de la Natural Historia de las Indias, edición de Manuel Ballesteros, Madrid, Historia 16. 
de comprobarse también, claramente, en el trabajo del mismo autor «La historia natural en Fernández de Oviedo» ${ }^{5}$. Dice en él Álvarez López sobre Fernández de Oviedo: «Sin ser un erudito humanista ni un científico profesional, lo que en su época hubiera estado vinculado casi necesariamente a la profesión de la medicina, tiene una honda inquietud por conocer y narrar, y esta tendencia casi innata se despliega en él con todo su poder al entrar por sus ojos la imagen de un mundo nuevo» ${ }^{6}$. Palabras que suscribo totalmente. Desde el punto de vista biográfico e histórico, es interesante la edición introducida por Ballesteros, que hace un conciso pero útil resumen del momento histórico y de la biografía de Oviedo y Valdés. Además de esto, hay estudios sobre las especies descritas por Fernández de Oviedo, en primer lugar por el propio Álvarez López, como ya citamos, y actualmente por Pardo Tomás y López Terrada.

Sin embargo, es curioso comprobar que las descripciones de las especies animales han sido mucho menos estudiadas que las especies vegetales, siendo que las de los animales son magníficas. Por esta razón decidimos analizar este aspecto, centrándonos, en principio, en un sector de los animales enormemente importante desde todo punto de vista, utilitario o científico, las aves.

Las aves son animales antiguos, que aparecieron a finales del Jurásico, descendientes de los reptiles, que habían dominado durante millones de años - entre los 200 a los 65 millones de años, aproximadamente - apareciendo formas en cierto modo intermedias, como el Achaeopteryx lithographica, fósil encontrado en la zona de Baviera.

Se diferencian esencialmente de los reptiles por poseer sangre caliente, los que les otorga una gran libertad, tener el cuerpo cubierto de plumas -escamas modificadaslo que contribuye a mantener su temperatura, además de su característica esencial, que es la de volar. La observación permite diferenciarlas por el tamaño y el color del plumaje, y un estudio más cercano permite comprobar las características del pico y las patas, que ofrecen gran información sobre la vida de las aves. También es útil observar las costumbres -alimentación, nidificación, huevos, etc- y el medio donde viven. Sin embargo, hay que señalar que, a menos que sean aves muy llamativas, o que se expongan con claridad a la observación, no es nada fácil poder verlas y describirlas con detalle. Y menos en la época en que no existían prismáticos. Digo esto para llamar la atención sobre la calidad de las descripciones realizadas por Fernández de Oviedo, lo que nos indica, además, paciencia y persistencia. Por otra parte, muchas de las aves, por su valor alimenticio, aporte de proteínas fundamental en la alimentación de los tiempos medievales y renacentistas, eran bien conocidas por los

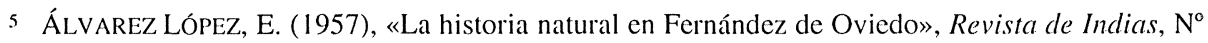
69-70

6 Ibidem, p.544.
} 


\section{LA DESCRIPCIÓN DE LAS AVES EN LA OBRA DEL MADRILEÑO GONZALO FERNÁNDEZ}

cazadores. Existen muchos libros de caza que describen aspecto y comportamiento, tanto de las aves que se cazaban como de las que se utilizaban para la caza, diversas especies de halcones la mayoría de las veces. Los animales y plantas útiles, fuera desde el punto de vista alimenticio, médico o estético, eran siempre mejor conocidos que los que no tenían algunas de esas características. Las aves, además de alimenticias eran decorativas y bellas por sus plumas y por sus cantos. Pero, insisto, no eran demasiado fáciles de describir si no llegaba, de alguna manera, a las manos del interesado.

Fernández de Oviedo, además de su consulta de la gran Historia Natural de Plinio, debía conocer libros de caza y albeitería, y debía haber tenido contacto con la caza, como toda persona de su tiempo, y más habiéndose movido en medios aristocráticos. Aunque él mismo dice, en la Historia General ${ }^{7}$, que sabe muy poco de cetrería. Pero Oviedo no era un naturalista, y describe vegetales y animales porque le gustan, interesan, le llaman la atención, y porque piensa y sabe que llamarán la atención de los europeos, de los personajes con los que se relacionó en España y en Italia. Su agudeza de observación y su capacidad descriptiva superaron, en muchos casos, a la calidad de la descripción de naturalistas, no de su época, sino de épocas, años, posteriores. Sin embargo, las descripciones de Oviedo no son sistemáticas. En algunos casos hace detalladas y completas descripciones, en otras despacha la especie con cuatro rasgos. Eso le diferencia, en alguna medida, de los médicos o naturalistas dedicados a la zoología — también pude aplicarse a sus descripciones botánicas-, que intentaban, quizás, hacer descripciones más homogéneas. Pero no siempre era posible, para unos y para otros. Debemos decir desde ahora, sin embargo, que cuando Oviedo describe un ave - y no solamente la nombra o la cita- en la gran mayoría de los casos se puede reconocer por lo menos su género.

Vamos a estudiar en este trabajo su forma de describir, e intentaremos valorarla, compararla en algún caso con otras descripciones de su tiempo, e intentar aportar la identificación actual del género y en algún caso de la especie, utilizando también las obras de autores que hiceron en sus trabajos esa determinación, como Enrique Álvarez López o Juan Ignacio de Armas ${ }^{8}$. La extensión de este trabajo no nos permite aportar la lista de las especies descritas y su identificación taxonómica.

La historia natural -e insisto en «historia natural», descripción de la naturaleza como conocimiento de ella - se caracterizó tanto por un humanismo que se va afirmando, como por una neta tendencia a preocuparse, por fin, de la observación directa

7 FERnÁNDEZ de OVIEDo, G. (1992) Historia General y Natural de las Indias, Biblioteca de Autores Españoles, tomo CXVIII, Madrid, p.70.

8 ARMAS, JUAN IGNACIO de (1888), La zoología de Colón y de los primeros exploradores de América, Habana, Establecimiento Tipográfico O'Reilly. FERnÁndEZ DE OviEDO, G. (1942), De la Natural Historia de las Indias, Madrid, Introducción y notas de Enrique Álvarez López 
de los objetos y los seres del universo. Es importante tener en cuenta el desarrollo de la imprenta, que se va convirtiendo en elemento muy importante para la difusión de los conocimientos que se van adquiriendo. Y quiero señalar también, como importante factor posterior en el tiempo, la curiosidad, interés y abundancia de nueva información aportada por el descubrimiento de la naturaleza americana, a la que contribuyó de forma esencial el personaje que aquí tratamos, Gonzalo Fernández de Oviedo, y sus descripciones de animales y plantas nuevas, pero semejantes, en continuidad y no ruptura con las especies europeas.

Desde el punto de vista de la zoología, es importante recordar que entre las obras más significativas recuperadas gracias al humanismo renacentista, se encuentran las de Aristóteles, tan influyentes hasta tiempos muy cercanos. Su obra, siempre presente en la ciencia, fue ampliamente difundida en recuperación original muy temprano, por la edición de Théodore Gaza (1483), y después, ya en el siglo XVI, por las ediciones de las obras completas del griego de 1529 y 1539, impresas en Lyon. En muchos casos, los naturalistas serán, fundamentalmente, humanistas eruditos, traductores, comentaristas y editores de obras de recopilación de informaciones antiguas, clásicas, y contemporáneas. «Naturalistas de gabinete», les llaman Petit y Théodoridès ${ }^{9}$, continuadores de la tradición enciclopedista, sin que ello signifique menosprecio por su obra, como en el caso de Konrad Gesner o de Ulisse Aldrovandi. Pero además, comenzaban a surgir los que, además de lectores de los clásicos, eran, gracias al estímulo de estos mismos y de los nuevos viajes y descubrimientos hacia oriente y occidente, observadores directos de la naturaleza. Fernández de Oviedo, fue, como repetidamente hemos señalado, un gran observador; de los hombres, de sus acciones y hechos, de sus costumbres y de todo otro aspecto del universo, geográfico, animal, vegetal o mineral. Pero no era un individuo especialmente preparado para la observación natural desde un punto de vista académico, como fue el caso de grandes eruditos pero también observadores, como por ejemplo Pierre Belon o Guillaume Rondelet. Gracias a las nuevas observaciones, a los viajes y descubrimientos, durante el siglo XVI comenzarán y se desarrollarán colecciones con especímenes zoológicos. Debemos recordar que, en la mayoría de los casos, las observaciones de la naturaleza suelen tener un interés práctico, médico o alimenticio fundamentalmente. Las descripciones de animales suelen aparecer en libros de materia médica o de medicina, esencialmente anatomía - la anatomía comparada se fue convirtiendo en muy importantante - o en libros de cazadores, criadores o albeítares, o sea veterinarios. Pero irán surgiendo «especialistas», que comienzan a tener interés por la descripción de las especies en sí, sus características y por las relaciones de diversos tipos de animales, «se ravissants sur la contemplation des choses magnifiques», como decía Pierre mann

9 PETIT, G. et THÉOdORIDÈs, J. (1962), Histoire de la zoologie. Des origines a Linné, Paris, Her- 


\section{LA DESCRIPCIÓN DE LAS AVES EN LA OBRA DEL MADRILEÑO GONZALO FERNÁNDEZ}

Belon. El estudio de los animales había sido desarrollado, aguda y detalladamente por Aristóteles, que realizó en sus trabajos un análisisis comparativo de la anatomía funcional, fisiológica — elementos de la digestión, reproducción, audición, etc.—, de los diferentes «géneros» y estableciendo las bases sobre las que podrían construirse clasificaciones. Para ello, también incluye la psicología animal, el comportamiento, las costumbres: el Libro VIII de la Historia de los animales está dedicado a las bases de la psicología animal y al principio de continuidad en la naturaleza. Según este principio, uno de los tres esenciales de la concepción aristotélica — continuidad de la naturaleza, jerarquía de las formas vivientes, causalidad teleológica - de la planta parte una larga cadena de seres vivientes que, por gradaciones insensibles, llegan al hombre. Por lo tanto, el hombre está comprendido entre los animales, que son comparados frecuentemente, incluso en su comportamiento, con él. Aristóteles enuncia en realidad los principios fundamentales de una clasificación natural. Y el poder de su estudio se prolongará hasta el siglo XVIII. No podemos dedicar más espacio a su estudio. Las aves o pájaros son, dice Aristóteles, un género. «Los géneros, los más generales en que se divide el conjunto de los animales son los siguientes: se cuenta uno para los pájaros, uno para los peces y otro para los cetáceos. Todos estos animales son sanguíneos». Estos grupos o «géneros» le parecen claros, así como otros de los animales no sanguíneos. Pero el concepto es más complicado, porque se introduce la cuestión de la forma de reproducción —ovíparos, vivíparos etc.—en el resto de animales sanguíneos, según explica en el texto, en el que también se crea confusión por los términos que se refieren a «género» [genos] y «especie» [eidos] ${ }^{10}$, el carácter relativo de estas nociones que Aristóteles intenta explicar de alguna manera en su texto: «Los otros animales no están comprendidos en estos géneros (los antes citados); porque una sola especie no comprende diversas especies, pero unas veces la especie es simple y no admite ninguna diferenciación, el hombre, por ejemplo, y otras admite buenas diferencias, pero las especies subordinadas no llevan un nombre común» ${ }^{11}$. Estos conceptos serán esenciales en los siglos posteriores, influirán cla-

10 Voy a ofrecer las acepciones de cada una de las palabras según el diccionario, para que se vean los matices de ambos términos:

GENOS: nacimiento, origen; linaje, familia, raza; raza o especie; pueblo o nación; descendencia, prole, posteridad, vástago, hijo; patria; clase, género; clase, casta; naturaleza, índole.

EIDOS: aspecto, catadura, figura, forma; hermosura; idea, representación, imagen; clase, especie; manera de ser, índole, naturaleza, disposición.

Estas acepciones parecen orientar hacia un concepto de grupo, relacionado de alguna manera, de forma familiar, por línea generacional, o de tipo cultural, o de forma «racial», lo que coincide más con un grupo amplio como sería el «género». En el caso de eidos, hay una referencia mucho más individual al aspecto, forma, representación de alguien, lo que coincidiría más con el concepto de «especie». Pero indudablemente hay ciertos aspectos coincidentes, como la cuestión de «clase».

1 Aristóteles (1987), Histoire des Animaux, Librairie Philosophique J.Vrin, Paris, pp.80-81. 
ramente en Plinio y, evidentemente, en el período renacentista, tanto directamente, por sus propias obras como por las de otros autores. Por lo tanto, serán las ideas y conceptos que utilice, con mejor o peor habilidad, Fernández de Oviedo, declarado seguidor de Plinio. Los grandes grupos que se utilizaban corrientemente dependían en gran medida del medio en que vivían los animales. Uno de los más evidentes era el de las aves - siempre uno de los más claros, aunque se introdujera en él animales como los murciélagos- que a su vez solían clasificarse por ciertas características anatómicas muy evidentes y por los sitios en que habitaban. Pierre Belon (15171564), uno de los primeros estudiosos sistemáticos de las aves — pensemos que es muy posterior a Oviedo, y que publicó su obra ornitológica en 1555- empleó ambos conceptos para su propia clasificación. Esta misma información nos indica la gran escasez de obras zoológicas existentes en el siglo XV y comienzos del XVI. Los animales eran relativamente menos importantes desde el punto de vista médico, y en cierta medida quedaban un poco perdidos en obras como el Dioscórides, por ejemplo. Existían los Bestiarios, como el de Oxford o el Toscano, así como el Libro de las utilidades de los animales, manuscrito árabe que se encuentra en el Escorial y el Physiologus, obras medievales cargadas de simbolismo, y obras relacionadas con las utilidades de los animales, de su c:ía, cuidado y caza —en España se escribieron importantes obras de albeitería o veterinaria y de caza o montería- y existía, como obra cumbre, la Historia Natural de Plinio. Pero las obras renacentistas de zoología, y con ellas el estudio de las aves, no comenzaron a aparecer hasta mediados del siglo XVI. Quizás la publicación más temprana fue la descripción del viaje por el Mediterráneo y Cercano Oriente de Pierre Belon, Les observations de plusieurs singularités et choses mémorables trovées en Grèce, Asie, Égypte, Arabie et autres pays étrangers, aparecida en Paris en 1533. Las obras naturalistas dedicadas a los animales de K. Gesner (1516-1565), G. Rondelet (1507-1566), H. Salviani (1514-1572) o el propio Belon son de la década de los cincuenta, y el gran tratado de Ulysse Aldrovandi (1522-1605), cuya primera parte estaba dedicada, justamente, a las aves -Ornithologiae, tomus unus, alter, tertius et ultimus- es de 1599.

La obra de Fernández de Oviedo que tratamos apareció nada menos que en 1526, prácticamente sin más antecedentes que los clásicos, Aristóteles y Plinio, los bestiarios medievales y algunas escasas obras más. Hemos hecho hincapié, repetidamente, en que Oviedo no era un naturalista, simplemente quería describir y sorprender con sus relatos de la naturaleza americana. Pero su gran capacidad de observación y descripción hace que su Sumario sea un trabajo similar al de un naturalista, y pienso que, además, es esencialmente una obra de zoología. El Sumario comprende también interesantes informaciones geográficas sobre el viaje entre España y América, e información botánica sobre plantas importantes y sobre diversas actividades productivas, como las minas de oro, la pesca y las pesquerías de perlas. Pero el grueso de la obra se centra en los animales. De ochenta y seis capítulos, cincuenta y cinco están 


\section{LA DESCRIPCIÓN DE LAS AVES EN LA OBRA DEL MADRILEÑO GONZALO FERNÁNDEZ}

dedicados a los animales, y además otros dos se refieran a los pescados y pesquerías y a las pesquerías de perlas. Y de ellos, veintiuno se refieren a las aves. En la Historia General, cuyos primeros diecinueve libros - en cuatro de los libros se comprenden las descripciones de animales - fueron publicados en 1535, aunque es evidente que Oviedo tenía un mayor conocimiento de más zonas de la llamada Tierra Firme, no aumenta el número de relatos de aves con relación al Sumario, aunque sí mejora algunas descripciones, pues añade detalles o explica otras características, lo que permite mejorar el conocimiento de la especie, más si se unen ambas descripciones $^{12}$. Hay que indicar, por otra parte, que en el resto de los abundantes textos que comprenden la Historia General, dedicados a describir los sucesos y hazañas de la conquista y exploración de los territorios que hoy comprenden zonas de Colombia y Venezuela, de Panamá, Costa Rica y Nicaragua - las zonas que el conocía personalmente- así como los relatos del descubrimiento, exploración y conquista de los territorios lejanos del resto de América, aparecen muy pocas descripciones de animales. Como excepciones, cuando habla de la región de Santa Marta ${ }^{13}$, se refiere a diversos animales y entre ellos dice que hay aves de rapiña, pero son sólo unas pocas líneas. Se puede señalar también su descripción de los bisontes ${ }^{14}$. Hay una descripción de los pingüinos cuando relata el viaje de Magallanes, en la que dice: «Hay unas aves tan grandes como ánsares, que no saben ni pueden volar, porque no tienen alas, sino unos alones como de toñina ${ }^{15}$, u otro pescado de aquella manera, y en todo lo restante tienen muy linda plumas, sino en las alas o aletones, que no tienen alguna; de las cuales aves, estos españoles tomaban muchas, e desollábanlas para comerlas» ${ }^{16}$.

Creo que es importante, desde el punto de vista del estudio de la historia de la zoología, y de las aportaciones que la nueva visión renacentista de la naturaleza ofrecerían, señalar el valor e interés de las tempranas descripciones del madrileño Gonzalo Fernández de Oviedo, que, además, insistía especialmente en indicar la localiza-

\footnotetext{
12 Gonzalo Fernández de Oviedo dedica los libros XII, XIII, XIV y XV de su Historia General a los animales. En el Libro XII trata de los animales terrestres, dice que siguiendo a Plinio pero también su propio interés, hablará de los animales que allí se encontraban al llegar Cristóbal Colón. En el Libro XIII trata «de los animales de agua», y en el XIV dice «Comienza el libro décimo cuarto de la Natural y General Historia de las Indias, islas y Tierra Firme del mar Océano; el cual tracta de las aves», que comprende diez capítulos, bastantes menos que los que dedica a ellas en el Sumario. En el Libro XV «tracta de los animales insectos».

13 «Séptimo Libro de la segunda parte, que es vigésimosexto de la Natural y General Historia de las Indias islas y Tierra Firme del mar Océano; el cual tracta de la provincia de Sancta Marta».

14 Oviedo, Historia General, Libro XVII de la segunda parte.

15 En la zona del Río de la Plata se llama todavía «tonina» a cierto tipo de delfines muy abundantes en las costas.

16 Oviedo, Libro XX, Capítulo VIII.
} 


\section{RAQUEL ÁLVAREZ PELÁEZ}

ción geográfica de las especies, de las que hablaba. En muchos casos señala que, según la zona en que se crían, o en que viven las especies, hay diferencias entre unos y otros especímenes. Quiero insistir, también, en la idea, que ya manifesté en $L a$ conquista de la naturaleza americana, de la importancia que tuvo el descubrimiento de esa «nueva naturaleza» en el desarrollo de esa visión también nueva que despertaba, tanto por el aporte cuantitativo de especies, como por esa percepción, que siente y manifiesta rápidamente Oviedo, de la semejanza entre las naturalezas europea y americana, aunque con una serie de diferencias que hay que indicar y que exige una gran capacidad para matizar y una gran agudeza para observar. Es el nacimiento de una nueva actitud comparativa - que después veremos expresada con cargas de valoración por grandes naturalistas como Buffon ${ }^{17}$ - que Oviedo, insisto, representa de forma magnífica, y que habría que resaltar hasta que consiguiera romper la barrera de las lenguas y conocimientos extranjeros, como tiene que suceder también con la obra de Hernández ${ }^{18}$. Pensemos que en obras tan reputadas como La zoologie au seizième siècle, de Paul Delauney apenas le dedica una línea, y le llama Gonzalo Hernández de Oviedo y Baldy - en lugar de Valdés-, que lo mismo sucede con la historia de la zoología de Petit y Théodorides o con otras obras francesas o anglosajonas dedicadas a la naturaleza. Sólo el italiano Antonello Gerbi ha sabido valorar las aportaciones de Fernández de Oviedo. Este sutil cambio que produce el contacto con la naturaleza americana, que se observa practicamente en todos los que hablan de ella, se manifiesta también, y es una sensación clarísima, cuando se comparan estas obras con las europeas, en la desaparición, casi completa, de los aspectos monstruosos de la naturaleza. Aunque en las crónicas americanas aún queda algún animal extraño, inexistente, todo manifiesta un carácter poco «amenazante», no aparecen ya esa especie de monstruos nacidos de un tenebroso más allá, peligrosos, más que por sus características de fiereza, por esa amenaza de lo desconocido. Animales cargados de contenido simbólico religioso, imbuidos de esencia diabólica, que aparecían en los bestiarios medievales, se conservaban, y se mantuvieron en muchas de las obras del siglo XVI, incluso en las más famosas. Las obras americanas se despojaron muy rápidamente de esa carga simbólica, como podemos ver en la obra de Fernández de Oviedo.

Demostraré, pues, la importancia de las tempranas descripciones de Oviedo, y para ello me serviré del ejemplo de un ave conocida también en Europa, que arrastraba, además, una importante carga simbólica —que después veremos- y que me permiti-

\footnotetext{
17 Sobre la ciencia americana en el siglo XVII, consultar la obra de PESET, J.L. (1987), Ciencia y libertad, C.S.I.C., Madrid.

18 Esperamos contribuir también al conocimiento de este médico y naturalista español, Francisco Hernández, a través de la edición del compendio de su obra, realizado por el médico napolitano Nardo Antonio Recchi en el mismo siglo XVI, que publicará la editorial Doce Calles con el título de El manuscrito de Recco "De materia medica Novae Hispaniae Libri Quatuor».
} 


\section{LA DESCRIPCIÓN DE LAS AVES EN LA OBRA DEL MADRILEÑO GONZALO FERNÁNDEZ}

rá comparar las descripciones del madrileño con otras, anteriores y posteriores. Veamos, entonces, la descripción de los pelícanos, «alcatraces» según le llamaban los españoles. Oviedo comienza insistiendo en este punto - como lo hará siempre en su obra con los productos naturales- «que llaman alcatraces» o que «están debajo del nombre de alcatraces». Oviedo ofrece una descripción del pelícano en cada una de sus obras, Sumario e Historia, en los que hay unos matices diferenciales que señalaré, para que se vea los progresos de Oviedo en su observación de la naturaleza, y su interés en señalar las pequeñas diferencias entre, en este caso aves, las especies y variedades. En su descripción explica tanto las características anatómicas externas, como el comportamiento de estos animales. Veamos sus textos. Analicemos, pues, la descripción de los pelícanos, como ya he dicho mítico y antiguo animal ${ }^{19}$.

19) Con respecto a la clasificación de estas aves, podemos decir que Enrique Álvarez López, dice, en sus notas al Sumario, p 211, que esta especie es la que hoy llamaríamos Pelicano Pardo, Pelecanus fuscus L. Sin embargo todas las clasificaciones actuales lo identifican con el pelícano pardo, Pelecanus occidentalis. Juan Ignacio de Armas se refiere en su libro citado, (publicado en 1883) pp 134-135, a las diferentes especies que el considera que han sido citadas por diversos cronistas de indias, y nos dice:

«L-PELECÁNIDAS

204-PELECANUS FUSCUS; alcatraz

Alcatraz grande- Oviedo. Sum. 37; XIV, 1.

Onocrótalo- Herrera. I, 10, 13.

Atotoli- Sahagún. XI, 2, 3.

Atototl- Hernández. Aves. 128 -Hern. p 673.

Grand gosier- Dut. II, p 271.

Relata Herrera que en 1514, al salir de Santa Marta para Cartagena la escuadra de Pedrarias, uno de los alcatraces salió de tierra, llegó a la nave capitana, dio luego una vuelta a toda la flota y cayó muerta; lo cual se tuvo como indicio de las desgracias que iban a suceder:

Esta especie, abundantísima en las Antillas, en el mar Caribe y en el golfo de México, se encontró también en el Pacífico. Oviedo describe el hermosos espectáculo que ofrecían en la bahía de Panamá cayendo sobre las sardinas, durante la alta marea. Torquemada, con relación a un sacerdote que iba en la expedición enviada por el Conde de Monterey a explorar las costas de California, cuenta que en una isla se halló un alcatraz con un ala rota, y amarrado con una cuerda, y a su alrededor grandes montones de sardinas, traídas al prisionero por los otros alcatraces; no siendo ese hecho, sino el resultado de un ardid de aquellos indios, que acudían allí a proveerse de pescado.

205- PELECANUS ERYTHRORHYNCHUS; en México alcatraz blanco.

Atotoli- Sahagún. XI, 2, 3.

Atototl- Hernández. Av. 8? 128? p 672.

De esta especie dijo Faber que tiene dientes en el pico, y así lo representa en su grabado, con el título de Onocrotalus mexicanus dentatus, a diferencia del Pelecanus fuscus, a que llama non dentatus. El mexicano Clavigero, aceptando ese aserto de un hombre que nunca estuvo en México, aseguró que había dos especies de alcatraces, una con el pico liso y la otra dentado. Pero ya Buffon había objetado que si algunos alcatraces presentaban escotaduras en el pico, éstas serían sin duda alguna accidentales. Cortés llevó varios ejemplares a España, en 1528».

La Enciclopedia Salvat de las Ciencias, pp 240-243, dice, resumiendo:

Orden Pelicaniformes 
Comienza Oviedo con el nombre, concepto que era esencial en el proceso renacentista humanista, que había incluso sido el aspecto esencial de obras sobre la naturaleza y la medicina, que habían dedicado gran parte de sus esfuerzos a exponer los nombres en diversas lenguas de las distintas especies, convirtiéndose en grandes enciclopedias. Y es también en Oviedo, una demostración de su preocupación por la nomenclatura de las especies encontradas en el Nuevo Mundo, aspecto que, en cierta medida, le desesperaba. Oviedo señalaba, por un lado, insistentemente, que los españoles llamaban a los animales por la semejanza con los conocidos. Pero él insistía siempre en las diferencias, y es evidente, en sus descripciones, que las busca, intenta detectarlas. Ve que los animales son parecidos, pero que tienen diferencias, que no son exactamente lo mismo, que la diferencia que a menudo encuentra no entra en la variabilidad normal entre individuos. También le interesa explicar, cuando puede hacerlo, los distintos nombres existentes entre los diferentes territorics americanos, sobre todo, por ejemplo, entre las islas y Tierra Firme. Oviedo insiste siempre en que los españoles llamaban con un nombre a las especies, pero éstas no eran verdaderamente "eso" conocido en Europa. En el caso del pelícano, dice que son llamados corrientemente alcatraces por los españoles, aunque no sean verdaderos alcatraces. A pesar de ser, por propia confesión, seguidor de Plinio en las cosäs de la historia natural, no cae Oviedo en el error que comete Francisco Hernández, —el médico toledano enviado por Felipe II a Nueva España, a México, para estudiar los productos medicinales y la naturaleza en general de las nuevas tierras de posesión española ${ }^{20}$ - en su descripción, que comienza diciendo que el «ATOTOTL» — nombre en náhuatles el animal que los griegos llamaban onokrótalon, cuando el nombre en griego, tal como puede verse en la obra de Aristóteles era «pelekán». Quien le llamaba onocrótalo era Plinio, como puede comprobarse en la propia traducción que hace Hernández de su Historia Natural.

Oviedo señala, en la Historia General, que aunque estos «alcatraces» se parecen a los que se ven en las costas de España, no lo son, va un paso más allá de lo que decía

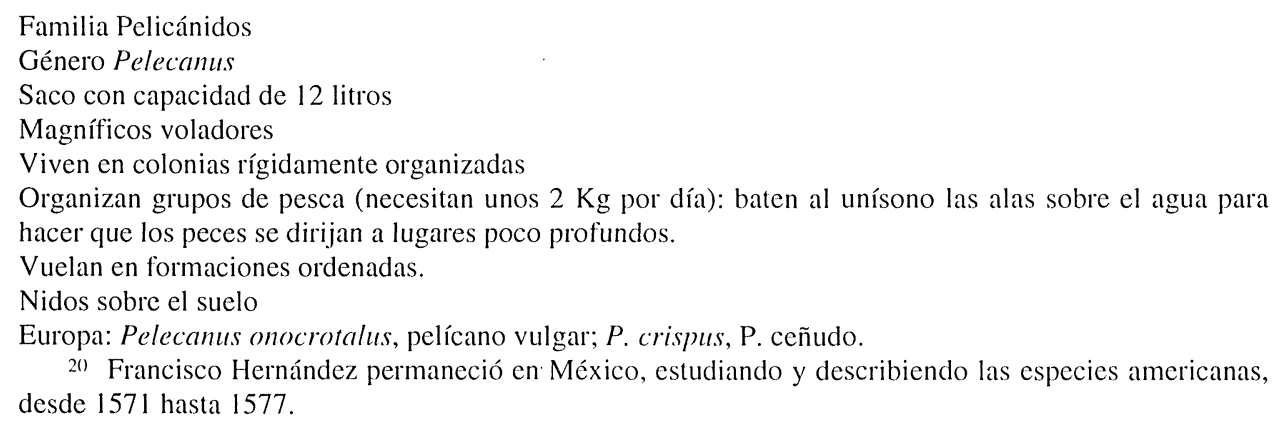


en su primer relato del Sumario. Nos dice el madrileño: «pero de los que agora diré, yo no los he visto ni creo que ahí haya, sino en estas partes, ni he oído decir que los haya en otras». La descripción es parecida en 1526 y en 1535, comparando a los pelícanos con los ánsares. Comienza con el tamaño - mayores que ansarones o grandes ansarones, nos dice- - s sigue con el aspecto exterior: plumaje en su mayoría pardo, algo en parte avutardado ${ }^{21}$, indica primero, y después, en la Historia General, que son todos pardos. Y agrega en esta obra una descripción más técnica; «las plumas mayores de sus alas son negras en los cuchillos y maestras». Después dirá, además, que en el pecho tienen el plumaje blanco.

Sigue Oviedo con la descripción del pico: Pico de dos palmos ${ }^{22}$, muy ancho cerca de la cabeza, va disminuyendo hacia la punta, con un grueso y grande papo. En la Historia - recordemos que es diez años después- lo describe con mucho más detalle: «Tiene un pico tan grande como dos palmos de luengo, e a par de la cabeza es tan ancho o más que una mano de hombre, e desde allí se va disminuyendo hasta la punta o fin del pico; pero en el extremo, donde es más delgado, queda más ancho que el dedo pulgar, e de allí declina algo para abajo, de manera de uña. E aquello de la parte superior del pico todo es duro, e la mandíbula baja se abre tanto e hace un papo que le va hasta el pecho». Para demostrar de alguna manera la gran capacidad de esa bolsa o «papo» acude Oviedo a su propia experiencia, diciendo que en 1521 vio en Panamá meter un sayo entero dentro del papo de uno de estos alcatraces. También lo vio hacer posteriormente en Santo Domingo, con una de estas aves - un especímen jóven, nos indica - alcanzada en un ala por un ballestero. Señala muy bien Oviedo la característica del extremo final del pico del pelícano, así como que la parte superior es la que es rígida, no así la inferior, la de la bolsa. Por otra parte Oviedo no dice nada de que el pelícano tenga escotaduras o algo semejante a dientes en el pico, error en el que caerá Hernández y en el que le seguirá Johannes Faber en la edición romana dei manuscrito de Recchi, a su vez compendio de la obra de Hernández ${ }^{23}$. La

21 Avutarda: L. de A. p.214: «abutarda, butarda. Whinnom 177, avutarda, abutarda, Otis tarda»; S. p.276, «Orden gruiformes, Familia Otídidos, Avutardas, Otis tarde; plumas blancas, negras, color castaño y nuez, manchadas en distintas formas». Se refiere, seguramente al color castaño.

22 El palmo, medida de longitud, corresponde a un cuarto de vara. La vara a su vez, tenía 835,9 milímetros. El palmo tenía, por lo tanto, 208,975 milímetros. Los dos palmos, el largo del pico sería, aproximadamente, de cuarenta a cuarenta y cinco centímetros.

2.3 La Historia Natural de Hernández, entregada a Felipe II y al Consejo de Indias no fue publicada tal cual, sino que pasó, por indicación real, a manos de un médico napolitano de la corte, Nardo Antonio Recchi, con el fin de que este hiciera, a partir de la de Hernández, un compendio de productos medicinales americanos. Este compendio tampoco fue publicado, por lo que sabemos hasta ahora, pero pasó a Italia con su redactor. Allí, tras una serie de circunstancias, fue utilizada por algunos de los integrantes de la Accademia dei Lincei, para realizar lo que fue la gran obra colectiva de la Academia, un libro de historia natural que se llamó Rerum medicarum Novae Hispaniae Thesaurus, que después también de muchos avatares editoriales, fue publicado en Roma, definitivamente, con la fecha de 1651. Para más 
representación del pelícano que aparece en el Rerum medicarum Novae Hispaniae Thesaurus, la edición romana citada, muestra la presencia de dientes arriba y abajo.

Describe también Oviedo las patas de las aves, diciendo que las tienen como las aves de agua, los ansarones o los alcatraces. Y en la descripción de 1535 dice: «Los pies tienen como de patos; pero tienen esta diferencia: que tienen un garrón en los talones, e desde aquel tienen continuada aquella tela de la pata a los otros dedos». Coincide con cualquier descripción actual de una de las características típicas del orden Pelecaniformes: "patas con los 4 dedos unidos entre sí por una membrana (para lo que incluso el cuarto dedo está desplazado hacia adelante, hacia el anterior interno)» ${ }^{24}$. Hernández, aunque señala que es un ave palmípeda, acuática, y que tiene «uñas negras y pies y piernas blancos», no habla de la diferencia que observa Oviedo, en relación con otras palmípedas, con respecto al quinto dedo. Sí habla el toledano de los ojos, que dice que son «amarillos con rojo».

Oviedo agrega a su descripción alguna observación acertada sobre la forma de volar de estas aves, diciendo que cuando vuelan llevan encogido el cuello y el pico pegado, de manera que parece que no tienen cuello. Hace, en ambas obras, un relato de un ave que vio en Flandes, - «hayna» o «haína», dice, ave que no hemos podido identificar-que se parecía mucho a ésta, que tenía los pies semejantes y comía peces vivos, pero, indica en la Historia, que no debía ser el mismo porque no tenía el «papo». Otro aspecto que Oviedo resalta, y que sigue siendo un factor importantísimo en el reconocimiento de las aves, es su comportamiento, alimentación y hábitat. En la Historia cuenta como pescaban individualmente para alimentarse: «Los cuales (los «alcatraces» o pelícanos), cuando vuelan, se suben en alto e tienen muy buena vista, e déjanse caer, juntadas las alas en el mar; e vienen hecho un ovillo, y del golpe que da, como es grande, salta mucho el agua para arriba, y él toma el peje e sale luego para suso sentado en el agua, e trágaselo». Y, dice, así lo hacen repetidamente, pescando en las costas y en los ríos. En el Sumario nos hace un relato aún más interesante del comportamiento de los pelícanos en aquella época. Nos dice primero la importancia de las mareas en la zona de Panamá, que es donde observó el comportamiento que va a contarnos. Y dice que cuando sube la marea, «cuando viene la dicha creciente, viene con ella tanta sardina, que es cosa maravillosa y para no poder

información se puede consultar, de Álvarez PelÁEz, R. (1995), «La obra de Hernández y su repercusión en las Ciencias Naturales», Asclepio, vol. XLVI, fasc. 2, pp. $27-44$; RECCHI, N.A., El manuscrito de Recco "De materia medica Novae Hispaniae Libri Quatuor", traducción de F. Fernández, introducción de R. Álvarez, editorial Doce Calles, Aranjuez, en prensa; LóPEZ PiñERO, J.M. y PARDo TOMÁS, J. (1994), Nuevos materiales y noticias sobre la Historia de las Plantas de Nueva España, de Francisco Hernández, Universitat de València-C.S.I.C., Valencia; Hernández, F. (1960-1984), Obras Completas, Tomo I, Vida y Obra de Francisco Hernández, por Germán Somolinos D'Ardois, U.N.A.M., México.

24 Enciclopedia Salvat de las Ciencias, Tomo 5, Animales Vertebrados, Pamplona, 1968, p 240 


\section{LA DESCRIPCIÓN DE LAS AVES EN LA OBRA DEL MADRILEÑO GONZALO FERNÁNDEZ}

creer la abundancia de ella sin lo ver;» Y luego nos cuenta lo que hacen «alcatraces» y rabihorcados de esta manera:

\footnotetext{
«Tornando a los alcatraces, así como viene la marea, y sardina con ella, ellos también vienen con la marea, volando sobre ella, y tanta multitud de ellos, que parece que cubren el aire, y continuamente no hacen sino caer de alto en el agua y tornan a caer, y se tornan a levantar de la misma manera, sin cesar; y así, cuando la mar se retrae, se van en su seguimiento los alcatraces, continuando su pesquería, como es dicho. Juntamente andan con estas aves otras que se llaman rabihorcados, de que atrás se hizo mención; y así como el alcatraz se levanta con la presa que hace de las sardinas, el dicho rabihorcado le da tantos golpes, y lo persigue hasta que le hace lanzar las sardinas que ha tragado; y así como las hecha, antes que ellas toquen o lleguen al agua, los rabihorcados las toman, y de esta manera es una gran deletación verlo todos los días del mundo» 25 .
}

Todos estos comportamientos están referidos en los libros actuales de aves, la pesca en grupo de los pelícanos, así como el robo de los peces por los rabihorcados: «Organizan grupos de pesca (necesitan unos $2 \mathrm{Kg}$ por día): baten al unísono las alas sobre el agua para hacer que los peces se dirijan a lugares poco profundos». Y una descripción corriente se parece también mucho a ésta de Oviedo. Por ejemplo, «Son de grandes dimensiones, con el cuerpo fuerte, patas cortas y fuertes y alas muy desarrolladas; el pico es muy grande, con la mandíbula superior terminada en gancho hecho que señala Oviedo en la Historia-. Es característica la bolsa subyugular formada entre las dos ramas de la mandíbula y la parte alta anterir del cuello; este saco, muy dilatable, con una capacidad de unos doce litros, sirve para retener la presa capturada bajo el agua como una red» ${ }^{26}$. Después de la descripción indicada añade el texto algunas indicaciones más con respecto al comportamiento y el hábitat de estas aves, y señala caracteres diferenciales entre las diferentes especies, indicando que el llamádo pelícano pardo es el Pelecanus occidentalis, de aspecto semejante al pelícano vulgar pero de diferente color: la cabeza y el cuello son blancos, pero el resto del cuerpo es pardo, tal como nos dice claramente Oviedo en su descripción.

Todos los autores, desde Aristóteles hasta nuestros días, señalaron el carácter migratorio de los pelícanos.

La descripción que hace, unos cuarenta años después, Francisco Hernández, se parece en gran medida a la de Oviedo, pero es mucho menos rica literariamente, y mucho menos viva ${ }^{27}$. La de Plinio, cuya obra había sido, según propia confesión de

25 FernándeZ DE Oviedo, G. (1986), Sumario de la Natural Historia de las Indias, Historia 16, Madrid, p 115.

26 Diccionario Enciclopédico Salvat Universal, (1969), Tomo 16, Barcelona, p 464, voz Pelícano.

27 Hernández, F. (1962) Obras Completas, p.347:

«Capítulo CXXVIII Del ATÓTOTL o ave acuática 
Oviedo, guía de su trabajo, o por lo menos, de las «distinciones e géneros de las cosas que escribo» ${ }^{28}$, es una descripción muy breve, que voy a transcribir para que se vea la escasa o ninguna deuda de Oviedo para con él. Dice Plinio —en la traducción de Francisco Hernández- en el capítulo titulado Del himantópode, onocrótalo y otras aves peregrinas, después de hablar de las primeras: «Son semejantes a los cisnes los onocrótalos, y no se podrían diferenciar si no tuviesen en la gargante una manera de otro segundo estómago, donde lo amontona todo este insaciable animal, porque es de cabida admirable, y luego, pasada la presa que tenía allí entera guardada [en] la boca, la torna a llevar, a manera de los que rumian, al estómago verdadero; tráhenlas de aquella parte de Francia que es cercana al océano septentrional « Y «El Intérprete», o sea el propio Hernández, comenta sobre esto que son aves conocidas pero raras en España, aunque muy abundantes en la Nueva España, donde las llaman, dice, alcatraces. Dice que son diferentes a los alcatraces que se ven en el mar junto con otras especies, tal como había ya señalado Oviedo. De la descripción de Plinio conviene señalar su indicación de que la bolsa no es un verdadero estómago.

Cuando se estudia la sucesión de descripciones, desde Aristóteles hasta hoy en día, pasando por los bestiarios medievales ${ }^{29}$, las obras árabes etc., se observa que la

\begin{abstract}
Aunque no ignoro que el ATÓTOTL, que los griegos llaman onokrótalon y nuestros compatriotas alcatraz, fue descrito por los antiguos y conocido del Viejo Mundo, con todo, como ha sido visto raras veces por los españoles y los autores difieren en su descripción, y por otra parte, aunque visitante, es muy frecuente en el lago mexicano, cuidamos de pintarlo y describirlo brevemente. Es pues un ave acuática, de donde toma el nombre, empenachada, palmípeda, mucho más grande que el cisne y nada comestible; sus plumas son en su mayoría blancas tirando a leonado, aunque las de las alas son en gran parte negras (lo cual sucede principalmente en el macho); tiene uñas negras y pies y piernas blancos, así como el pico, que es de ocho dedos de largo y bordeado de pequeños dientes, encorvado en la punta, y tiene por debajo aquella gran cavidad que es como un amplio almacén de alimentos; los ojos son amarillos con rojo. Se alimenta de los peces que arrebata, y suele por eso encontrarse junto a los lagos y ríos y también en el mar».

28 Oviedo, Historia General y Natural, Libro 12 de la Primera parte, Proemio.

29) Transcribiré lo que dice en El fisiólogo, uno de los bestiarios medievales más difundidos, para que se vea cual era la tónica descriptiva de estas obras, pues en todas se trata de estas aves de la misma manera. Dice el Capítulo VIII de esta obra:

«El pelícano sobresale sobre todas las aves en amor a la prole. La hembra se echa en el nido, custodiando a sus polluelos, les da calor y los abraza y llega a herirles con sus excesivas caricias, hasta el punto de perforar sus costados y morir aquellos. Transcurridos tres días llega el pelícano macho y encuentra muertos a los polluelos; se angustia sobremanera y arrebatado de dolor golpea su propio costado y lo taladra y fluye la sangre que, gota a gota, deja caer sobre la heridas de los polluelos muertos, los cuales, de esta manera, son devueltos a la vida». Después venía la interpretación, lo que demuestra la intención puramente simbólica y religiosa de este tipo de obras. La interpretación reza: «Así Nuestro Señor Jesucristo, cuyo costado atravesó una lanza, y del que brotó al instante sangre y agua, derramó su sangre sobre sus hijos muertos, esto es, sobre Adán y Eva y el resto de los profetas y sobre todos los muertos, e iluminó el universo mundo, y trajo aquéllos a la vida de nuevo mediante los tres días de su sepultura y su resurrección». De ahí que dijera por el Profeta: «Me parezco al pelícano del yermo». El pelícano, pues,
\end{abstract}


diferencia más importante no se encuentra en la descripción en sí, sino en gran medida en la concepción taxonómica y en la integración de los diferentes grupos de animales en el conjunto de la naturaleza. Es un punto interesante que espero exponer en otra parte, pero que ya no tiene cabida en este trabajo.

Muchísimo habría que decir sobre la importancia de estas nuevas descripciones, tan naturales y directas de Oviedo, así como sobre la publicación y difusión de sus obras sobre historia natural -el Sumario y la Primera parte de la Historia General y natural, que comprendía los primeros diecinueve libros- difusión que fue amplia e importante, tanto directamente como a través de las publicaciones del italiano Gian Battista Ramusio ${ }^{30}$, colecciones de viajes y exploraciones de la época. Espero que este breve trabajo contribuya a demostrar la importancia que tuvo para la ciencia natural el descubrimiento de la naturaleza americana, y las descripciones que de ella hicieron muchos de los españoles que allí fueron, con Gonzalo Fernández de Oviedo como figura esencial en la primera mitad del siglo XVI.

\footnotetext{
era el símbolo de Cristo. Ésta, con variaciones, fue una de las leyendas sobre este animal más difundidas en la Edad Media, y parece que la idea de que resucitaba a los polluelos tendría relación con la forma en que les alimenta, a partir de su bolsa llena de pescado.

Texto tomado de Sebastián, S. (1986), El Fisiólogo. Atribuido a San Epifanio. Ediciones Tuero, Madrid, pp.53-54.

30) Ramusio, G.B. (1556), Navigationi et viaggi, Terzo volume, Giunti, Venezia. El tercer volumen estaba dedicado totalmente al Nuevo Mundo. Ramusio incluyó el Sommario e storia delle Indie Occidentali di Gonzalo Fernández de Oviedo.
} 